\title{
An Interesting Case of Central and O bstructive Sleep Apnea in A Patient of Congestive Heart Failure with Unmasking of CSA's Following CPAP Use
}

\author{
D. Bhattacharya, M. K. Sen, S. Chakrabarti, N. K. Gupta, J. C. Suri

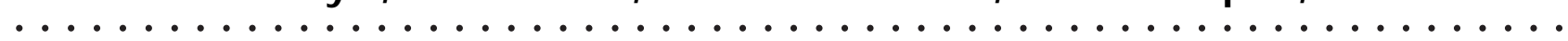

Indian J Sleep Med 2006; 1.2, 109- 117

See end of article for authors affiliations

Address for correspondence:

D. Bhattacharya

Department of Pulmonary,

Critical Care \& Sleep

Medicine, Vardhman Mahavir

Medical College \&

Safdarjang Hospital

New Delhi

\begin{abstract}
An elderly man with acute anterior wall myocardial infarction who underwent medical therapy followed by angioplasty and stenting was referred to our centre for evaluation of sleep-disordered breathing. The gentleman had moderate hypothyroidism for which he was on replacement therapy. At our centre PSG showed OSA for which a trial of CPAP was given. O $n$ correction of OSA by CPAP, presence of underlying CSA was unmasked. The patient improved over time on intensified medical therapy, continuous use of CPAP and regulated thyroid replacement therapy.
\end{abstract}

Keywords: O SA: O bstructive sleep apnea, CSA: Central Sleep apnea, CPAP: continuous positive airway pressure, BiPAP: bilevel positive airway pressure, PSG : polysomnography.

\section{Introduction}

eart failure (HF) is a major risk factor for sleep related breathing disorders. U nfortunately, they remain mostly under diagnosed because of lack of awareness among primary care physicians and cardiologists. In the US, heart failure affects 1.5 - $2 \%$ of the population (1) and upto $6-10 \%$ among persons older than $65 \mathrm{yrs}$. Various studies in patients of left ventricular heart failure have shown that at least $45 \%$ have an apnea hypopnea index (AH I) of $>10$ /hour and $40-80 \%$ have an $\mathrm{AHI}>15 /$ hour. (1) Tremel et al (2) have shown that $82 \%$ of $\mathrm{HF}$ patients who have acute LVF had sleep disordered breathing, out of which $75 \%$ had CSA and 25\% had OSA. Sin et al (3) and Javaheri et al (4) studied $450 \& 81$ patients and showed $72 \%$ of CSA \& $33 \%$ OSA and $40 \%$ of CSA \& $11 \%$ OSA respectively. H owever few studies have reported a higher incidence of OSA's in patients of H F. (5).

In this report we present a case of $\mathrm{HF}$ with OSA where presence of CSA became apparent only after institution of CPAP. The patients OSA/CSA over time were controlled with intensive medical therapy and overnight CPAP therapy.

\section{CASE REPORT}

An elderly (73 yrs) male, non-smoker, non-alchoholic patient was admitted to a city hospital in mid 2003 with acutechest pain. H ewas diagnosed to have acute anterior wall myocardial infarction. He was given thrombolytics (streptokinase) besides supportive care. As the patient was drowsy, complained of breathlessness and serial ABG 's suggested type II respiratory failure with academia he was given a BiPAP trial. Since the patient continued to have persistent chest pain, he was taken up for coronary angiography; which showed a $80 \%$ block of the left anterior descending artery. An angioplasty with stenting was done for the blockage. ECHO studies showed concentric LVH with severe hypokinesia of apical $1 / 3$ of inter ventricular septum, anterior wall and apical half of lateral wall. There was diastolic dysfunction with an ejection fraction of $30 \%$. As there was little symptomatic improvement he was referred to our centre 
for evaluation and further management.

The patient gave history of snoring for 2 yrs and excessive daytime sleepiness for nine months. There was history of choking/ abruptly getting up from sleep and observed pauses in breathing during sleep. There was history of nocturia and a gain in weight in the past 8-9 months. The patient was known to have $\mathrm{HT}$ and $C A D$ for which he was on regular treatment for the last eight years. There was history of PSVT for which he underwent radio frequency ablation in 1996. Thepatient had also undergone TURP for BH P in 2002 and was on replacement therapy for hypothyroidism since $M$ arch 2002.

O $n$ examination, the patient was an elderly man with a pulse of 100/min, RR 22/min \& BP on supine position of $140 / 80 \mathrm{mmH} \mathrm{g}$. He had a height of $160 \mathrm{~cm}$ and a weight of $83 \mathrm{Kg}\left(\mathrm{BMI}: 32 \mathrm{Kg} / \mathrm{Ht}^{2}\right)$. H is neck circumference was $43 \mathrm{~cm}$ and corrected neck circumference $50 \mathrm{~cm}$ (correction factor $+4 \mathrm{~cm}$ for hypertension and $+3 \mathrm{~cm}$ for snoring (6). $H$ is CVP was raised and he had bilateral pitting edema of the feet. Examination of the chest was normal except for bilateral inter and infra scapular inspiratory crackles. Examination of CVS and abdomen was essentially normal. Examination of the CN S revealed a slow relaxation of deep tendon reflexes.

An EN T examination revealed a grade II tongue, thick, low palate; tonsillor bulk grade II; posterior pillars were splayed wide with inter pillar distance of $<20 \mathrm{~mm}$. Theuvula was $>10 \mathrm{~mm}$ and edematous. Thenose showed evidence of $B / L$ chronic hypertrophic changes. The larynx was normal. (7)

On investigation his haemogram, routine urine examination, serum biochemistry, electrolytes and lipid profile were normal. The thyroid function test was deranged (free T 3: $0.42 \mathrm{pg} / \mathrm{ml}$ (1.42-4.2), Free T 4: < $.15 \mathrm{ng} / \mathrm{dl}(0.8-2.0) ;$ and T SH : $>40 \mathrm{lu} / \mathrm{ml}(.25-5.0)$. $\mathrm{H}$ is $X$ ray chest was normal. ECG showed evidence of old anterior wall MI. The PFT showed a mild obstructive ventilatory defect (FVC-1.72L 57\%; FEV 1: $1.27 \mathrm{~L}$ (55\%); FEV 1/FVC: 73.7\%; FEF: 25-75; 0.82 L: 38\% and SVC: $2.13 \mathrm{~L}(71 \%)$. Serial ABG 'sat this stage showed hypoxemia with mild hypocapnia. A repeat ECHO revealed findings similar to the previous study with an EF of $33 \%$. D espite intensive medical therapy with diuretics, ACE inhibitors, oxygen and theophyllin, there was no improvement in clinical features and hypoxemia, therefore, the patient was taken up for split night polysomnography.

The PSG showed evidence of severe obstructive sleep apnea with an $\mathrm{AHI}$ index of $60 \mathrm{hr}$. There was severe degree of oxygen desaturation with the lowest recorded $\mathrm{SaO}_{2}$ of $78 \%$, associated with snoring.

The patient was put on CPAP and pressure was gradually increased to $15 \mathrm{~cm} \mathrm{H}_{2} \mathrm{O}$, resulting in complete elimination of obstructive apneas, snoring and oxygen desaturation. Immediately after correction of the obstructive apneas the patient started showing episodes of periodic breathing with variable periods of central apneas. Initially it was thought that the central apneas could be the result of high CPAP pressure. However, with repeated adjustment of CPAP pressures and using the minimum pressure, which resulted in abolition of obstructive apneas the periodic breathing continued. Keeping in view the patients background of ischemic heart disease with $\mathrm{HF}$ and an EF of $33 \%$ it was presumed that the periodic breathing were due to cardiac failure which were being masked by the obstructive apneas. (Fig 1 to 4).

After institution of CPAP for sleep disordered breathing and intensified medical therapy for $\mathrm{HF}$, the patient's thyroid replacement therapy was stepped up. Follow up after three months showed normalization of thyroid functions and control of SD B on CPAP.

\section{DISCUSSION}

$\mathrm{H}$ eart failure (HF) affects 5-6 million $\mathrm{N}$ orth Americans and is increasing in prevalence. (8) In India heart disorders including coronary artery disease have attained epidemic proportions. Various pharmacological agents have had little effect in hospitalization \& death rates (8). Therefore, there is a need to develop newer, widely acceptable and cost effective approaches to the therapy of $\mathrm{HF}$.

An important limitation to the current guidelines for evaluation and management of chronic $\mathrm{HF}$ is their focus on the patient as he/she presents while awake.(9) This presupposes that the mechanisms that contribute to the pathophysiology or progression of $\mathrm{HF}$ are quiescent during sleep. Sleep normally is a time for cardiac relaxation, however, about $50 \%$ of $\mathrm{H} \mathrm{F}$ patients have OSA $\&$ CSA both of which disrupt the normal relaxing effects of sleep on the cardio vascular system and may actually worsen $\mathrm{HF}$. 


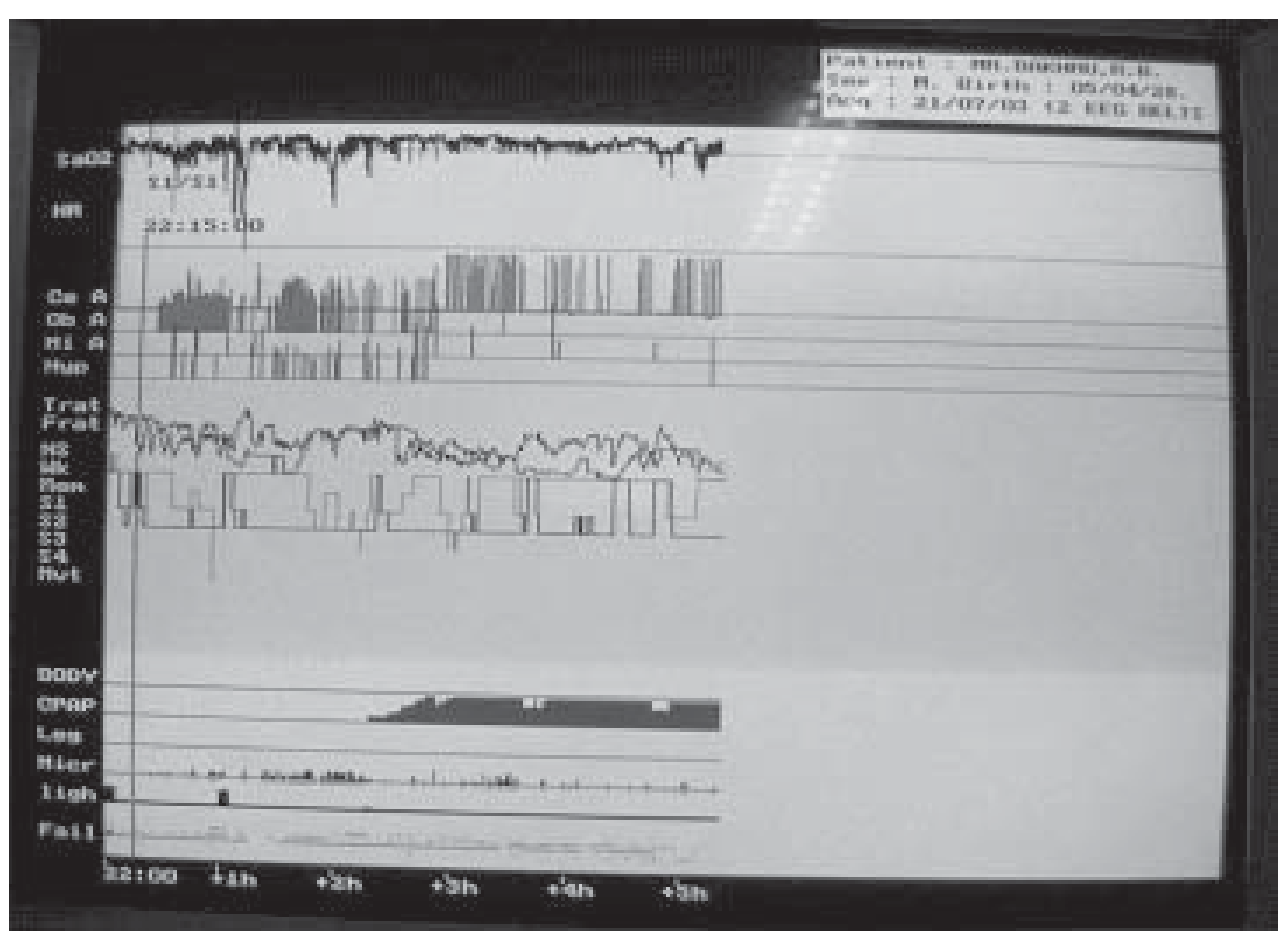

Fig 1: Whole night histogram of patient showing initial predominant OSA which after CPAP exposed underlying CSA, with improvement in saturation and snoring.

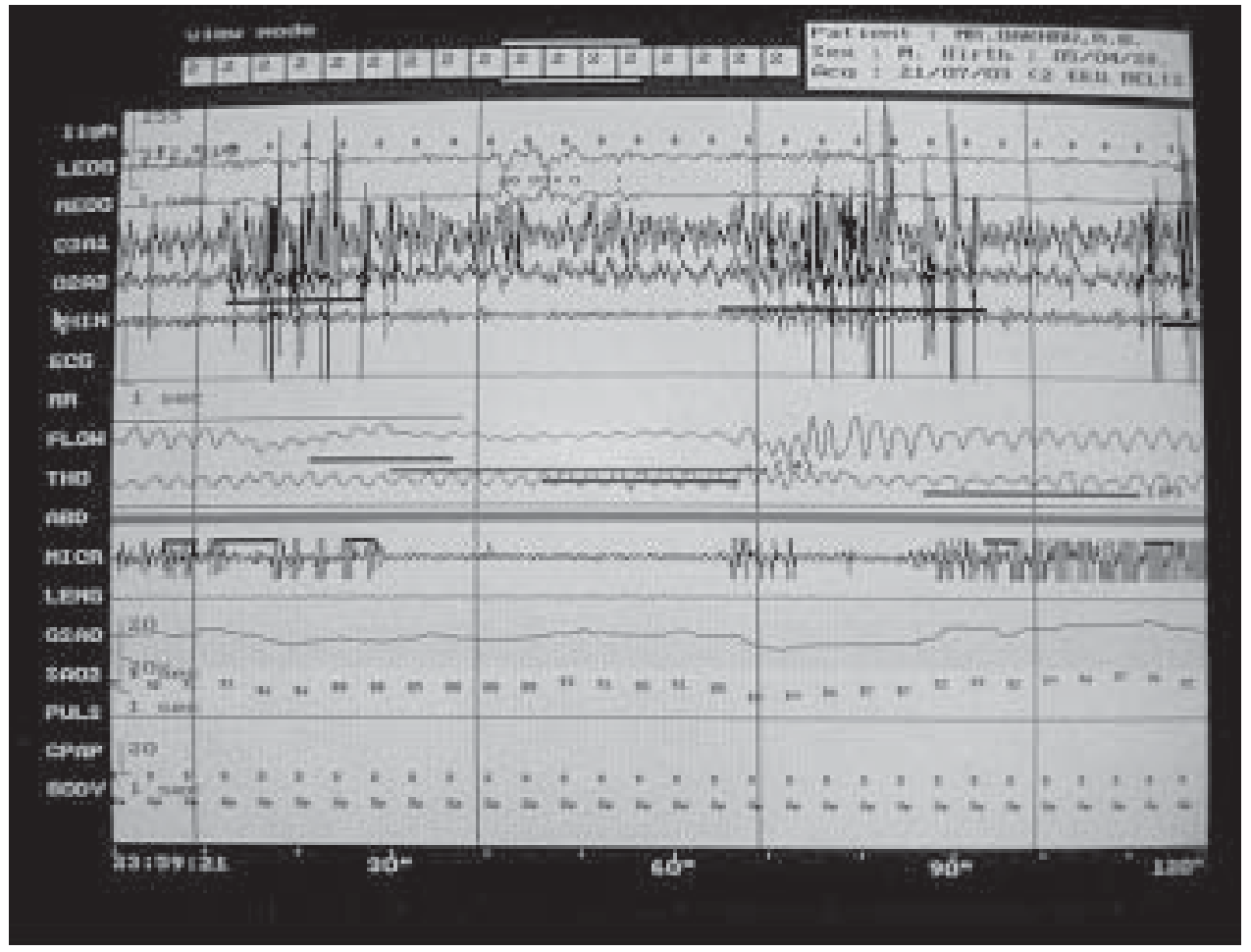

Fig 2: PSG of patient before application of CPAP showing an episode of OSA with snoring and desaturation 
112 An Interesting Case of Central and O bstructive Sleep Apnea in A Patient of Congestive HeartFailure with Unmasking of CSA'sFollowing CPAPUse

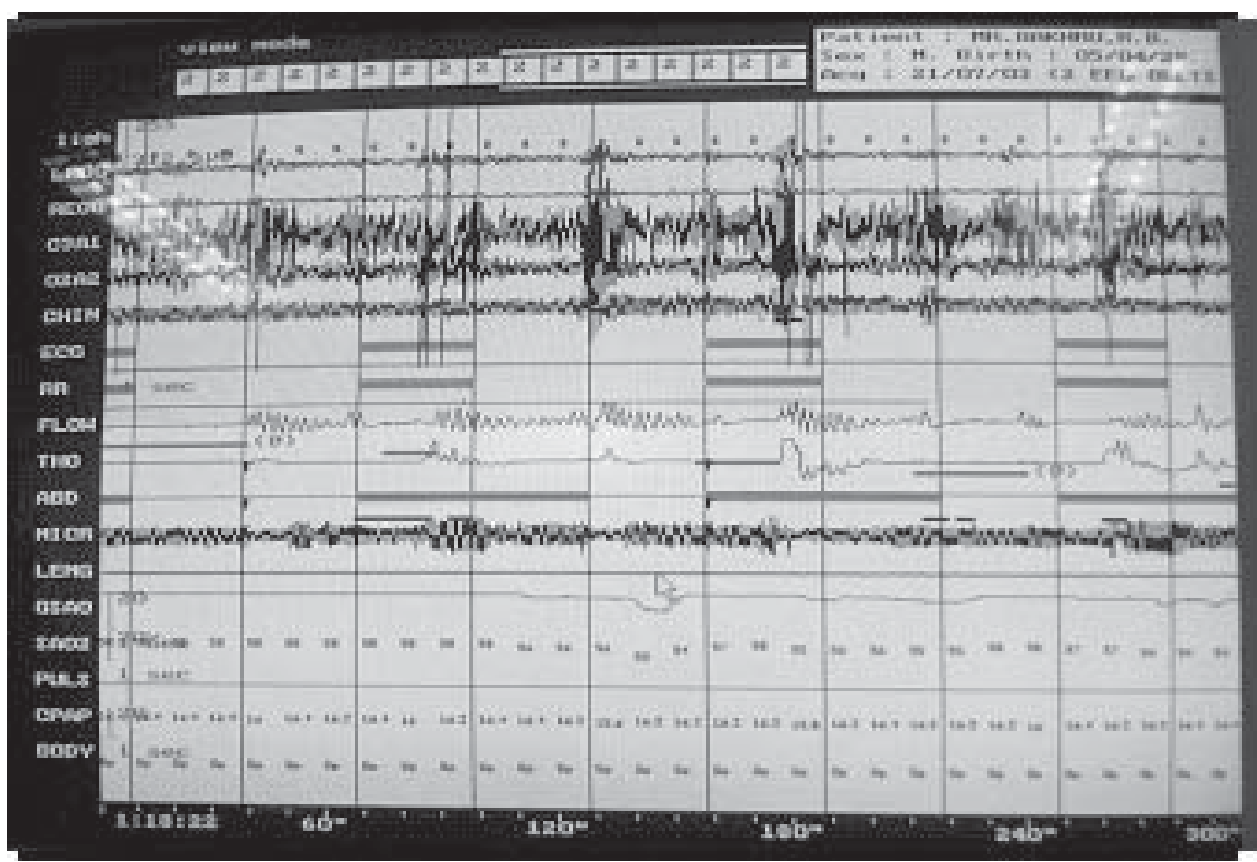

Fig 3: PSG of patient depicting presence of Cheyne Stokes respiration after institution of CPAP

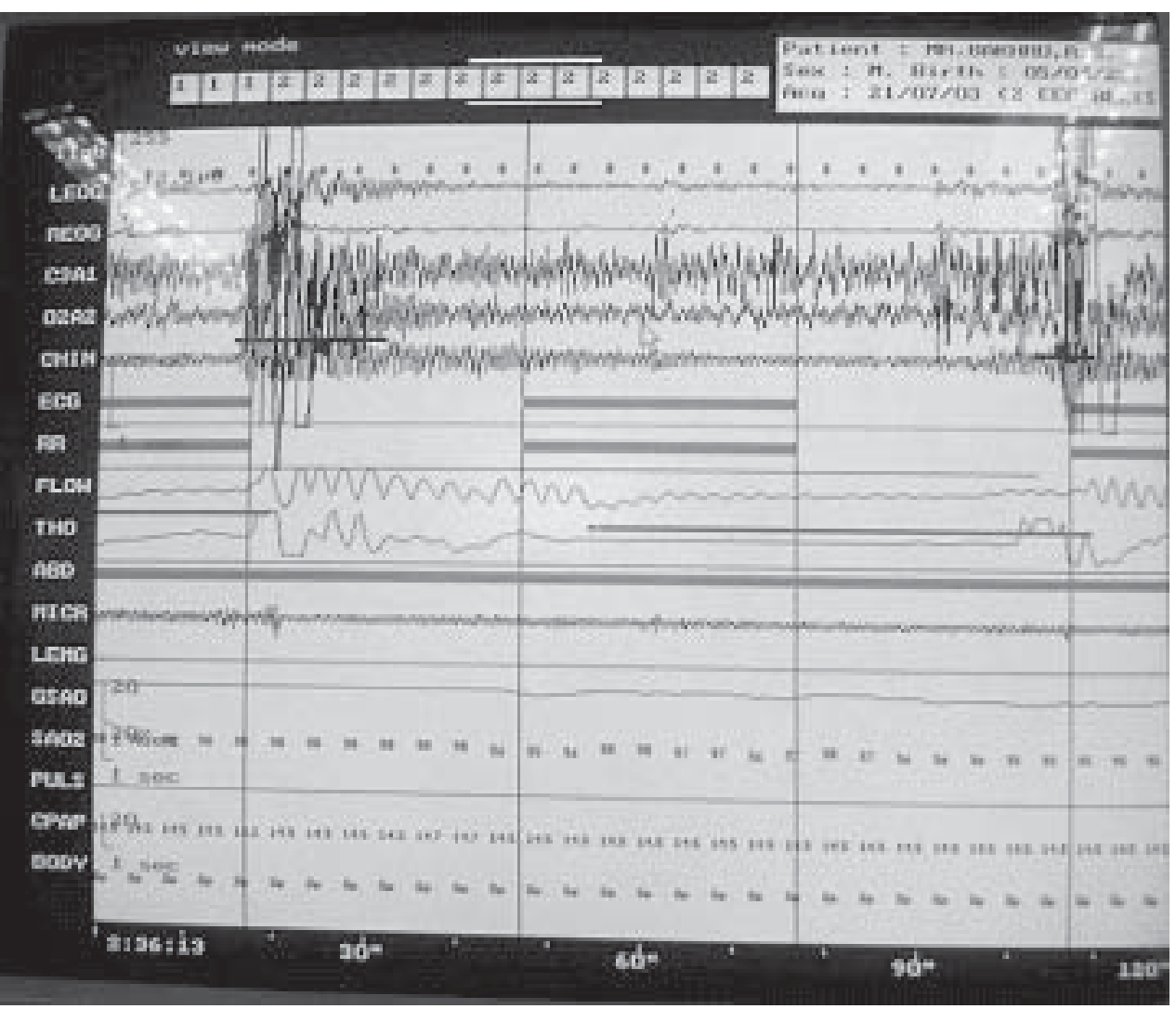

Fig 4: PSG of patient after institution of CPAP at a pressure of $14.5 \mathrm{~cm} \mathrm{H}_{2} \mathrm{O}$; showing periodic breathing (central sleep apneas). 
Looking at the risk factors, for OSA and CSA Javaheri et al (4) found OSA patients had significantly higher body weight $(112 \pm 30$ versus $75 \pm 16 \mathrm{Kg})$ and prevalence of habitual snoring ( $78 \%$ versus $28 \%$ ). H owever episodes of apnea and hypopneas (36 \pm 10 versus $47 \pm 21)$, episode of arousal ( $20 \pm 14$ versus $23 \pm$ 16 ) and desaturation (lowest saturation, $72 \pm 11 \%$ versus $78 \pm 12 \%$ ) were similar in the different types of apnea. Sin et al (3) found risk factors for CSA were male gender (odds ratio (OR) 3.50; 95\% confidence internal [CI] 1.39 to 8.84$)$, atrial fibrillation $(\mathrm{OR} 4.13 ; 95 \% \mathrm{Cl} 1.53$ to 11.14 ), age $>60 \mathrm{yrs}(\mathrm{OR} 2.37 ; 95 \% \mathrm{Cl} 1.35$ to 4.15 ), and hypocapnia ( $\mathrm{PCO}_{2}<38 \mathrm{~mm} \mathrm{H}$ g during wakefulness) (OR 4.33; $95 \% \mathrm{CI} 2.50$ to 7.52 ). Risk factors for OSA differed by gender: in men, only body mass index (BMI) was significantly associated with OSA (OR for BMI > $35 \mathrm{Kg} / \mathrm{ht}^{2} 6.10 ; 95 \% \mathrm{Cl} 2.86$ to 13.00$)$; whereas in women age was the only important risk factor ( $O R$ for age $>60 \mathrm{yr}, 6.04 ; 95 \% \mathrm{Cl} 1.75$ to 20.0). Our patient being about 73yrs, BM I of $35 \mathrm{Kg} / \mathrm{ht}^{2}$, male gender, with arterial $\mathrm{PCO}_{2}$ of about $38 \mathrm{mmH} \mathrm{g}$ (awake) had most characteristics associated with SDB in $\mathrm{HF}$.

The pathophysiology of OSA \& CSA is dissimilar. $O$ bstructive sleep apneas are caused by collapse of the pharynx in sleep. In patients of OSA the pharynx is narrowed and highly compliant. In this setting the superimposition of the normal withdrawal of pharyngeal dilator muscle tone at sleep onset causes the pharynx to occlude, triggering apnea. (10) 0 besity is the chief risk factor, because of layering of fat adjacent to the pharynx narrowsits lumen. (11) W ithdrawal of pharyngeal muscle tone during CSR (12) and shift of edema fluid (13) are also attributed as additional risk factors.

$\mathrm{HF}$ patients with CSA hyperventilate chronically due to stimulation of pulmonary vagal irritant receptors by pulmonary congestion. (14). This increases when the patient lies flat due to increased venous return producing hyperventilation and reduction in $\mathrm{PaCO}_{2}$ below the threshold for ventilation, triggering a central apnea.(15) followed by arousals (16). CSA's are sustained by recurrent arousals resulting from apnea induced hypoxia and the increased effort to breathe during the ventilatory phase because of pulmonary congestion and reduced lung compliance. The length of the ventilatory phase is inversely proportional to cardiac output, reflecting a delayed transmission of changes in arterial blood gas tension from the lung to the chemoreceptors(17). This was first demonstrated by Klein (18) and later by Pryor (19) in their studies. Theabove, along with large negative swing in intrathoracic pressure occurring in the hypercapnic phase of periodic breathing, adversely affect various cardiovascular functions and are potentially detrimental in presence of systolic and diastolic dysfunction and coronary artery disease.(20),(21) The effect of HF on OSA \& CSA, its pathophysiological aspects, clinical features and therapeutic options has been reviewed by Bradley \& Floras (8) (22) in their articles on the subject.

Clinical features of patients with $\mathrm{HF}$ and OSA are similar to those of OSA patients without H F. The patients being usually obese and have history of loud habitual snoring. Among patients with $\mathrm{HF}$ with CSA there are no disease specific symptoms. Patients who are awake during peak of ventilation after apnea may report paroxysmal nocturnal dyspnea (23). Although there is sleep fragmentation, only few patients of OSA or CSA (4) among patients of $\mathrm{H} \mathrm{F}$ complain of excessive day time sleepiness and therefore many of them remain occult (24). 0 ur patient however presented with a long history of snoring and EDS.

In some patients of HF, CSA and OSA coexist as seen in our patient. T kacova et al (25) noted a gradual shift from predominantly obstructive apneas at the beginning of the night to predominantly central apneas towards the end in such cases. They evaluated this by studying minute ventilation, transcutaneous $\mathrm{PCO}_{2}$, circulation time and periodic breathing cycle length during overnight PSG in 12 patients of CHF. They concluded that overnight shift from OSA to CSA is related to reduction in $\mathrm{PaCO}_{2}$ caused by increases in minute ventilation. Most importantly, the close relationship between overnight reduction in $\mathrm{PCO}_{2}$ and increase in circulatory delay suggests that the overnight shift in apnea type is linked to deterioration in cardiac function. $\mathrm{H}$ all et al (26) have also noted that this lung to chemo receptor circulatory delay owing to low cardiac output, and cycle length of periodic breathing are longer in CH F patients with sleep apnea than in patients with sleep apnea but normal cardiac function. This concept is consistent with the suggestion of Somers (27) that hemodynamic instability in patients with $\mathrm{CHF}$ may be related to instability in apnea type as well. Solin et al (14) demonstrated that $\mathrm{PaCO}_{2}$ is inversely related to the capillary wedge pressure in patients of $\mathrm{CHF}$ and frequency of CSA is directly related to the left ventricular filling pressure. Periodic breathing cycle length and lung to ear circulation time (LECT) areproportional to cardiac output suggestive of nightly fall in cardiac output were 
also shown by $\mathrm{H}$ all et al (26) \& T kocava et al (28). These studies raises the possibility that over months or years the presence of OSA could predispose HF patients to CSA which has more ominous implications.

Another confounding factor in our patient was the presence of hypothyroidism, where OSA is thought to occur due to deposition of mucopolysaccharides and protein extravasation into the tissues of the pharynx $\&$ tongue (29). 0 ther hypothesis suggested is abnormalities in ventilatory control during sleep (30) and blunted response to hypoxia (31). Central sleep apneas have been noted in hypothyroidism(32). The contribution of hypothyroidism in our patient to the CSA/O SAs cannot be commented on as the patient was also on CPAP during the follow up phase besides medical therapy for HF and regulated thyroid replacement therapy.

Though general therapeutic measures like weight reduction, abstinence from alcohol and sedatives (33) may reduce the severity of OSA, (34) CPAP remains the corner stone of therapy in OSA whether associated with or without HF. CPAP via nasal mask alleviates OSA, improves sleep quality, reduces daytime sleepiness, augments neurocognitive function, and may lower nocturnal and daytime blood pressure $(35,36)$. Regular CPAP use has also been demonstrated to increase the ejection fraction and improve dyspnea(37) in H F. There is no evidence that pharmacological agents used to treat $H F$ have any influence on the severity of OSA(38).

Treatment of central sleep apnea may be achieved in several ways $(23,39)$. Javaheri in a recent review has discussed all aspects related to treatment of central sleep apnea in HF (20). The principal reason for treating CSA is the potential to improve cardiovascular function, quality of life and longevity $(40,41)$. Because CSA is a manifestation of advanced $\mathrm{HF}$, the first consideration is to optimize drug therapy. Amongst these measures aggressive diuresis, angiotensin converting enzyme inhibitors and B blockers form the corner stone (13). Theophyllin also plays a role as a respiratory stimulant by competing with adenosine at some receptor sites. In the CNS theophyllin stimulates respiration by competitive inhibition of adenosine (42). Another drug helpful in treatment of CSA in H F is acetazolamide a carbonic anhydrase inhibitor that produce metabolic acidosis thereby stimulating the peripheral and central chemo receptors $(43,44)$. Supplemental nasal oxygen administered during sleep is a potent therapy for CSA in systolic heart failure $(45,46)$. Several studies $(47,48)$ have shown that apnea- hypopnea index decreases with oxygen inhalation. Randomized, placebo controlled double blind study has also shown that exercise capacity improves within a week of oxygen (49). This occurs perhaps, due to a reduction in ventilatory response to $\mathrm{CO}_{2}$ following a risein $\mathrm{PaCO}_{2}(50)$. Also, oxygen reduces sympathetic activity (51) and urinary non-epinephrine excretion (52). Although inhalation of $\mathrm{CO}_{2}$ suppresses CSA, this has little or no therapeutic role $(53,54)$.

If the above measures fail other non-pharmacological measures have to be resorted to. The chief therapeutic options here are various forms of non-invasive positive pressure ventilation including C PAP, BiPAP and adaptive pressure support servo ventilation, all of which alleviate CSA over a period of time $(41,55)$. H owever, thus far, the only intervention whose effects on cardiovascular outcomes have been evaluated is CPAP. CPAP helps by decreasing left ventricular after load (56), augmentsstroke volume (57), reduces cardiac sympathetic activity (58), decreases right and left ventricular end diastolic volume (59), ventricular ectopic beats (60), improves ejection fraction and improves quality of life $(61,62)$.

Bradley et al (63) in the CAN PAP trail have shown in 250 patients that although there was decrease the $\mathrm{AHI} \mathrm{I}$, nor epinephrine levels, improvement in mean $\mathrm{O}_{2}$ saturation, ejection fraction and six minute walk test; there was no difference in the event rates i.e. death and heart transplantation. Although improvement in cardiac function has been shown in patients in CSA with and without CSR, mortality advantage was only seen in patients of CSA with CSR (64). Even without CPAP, presence of CSR with CSA increases mortality in patients with $\mathrm{CHF}$ (65). O ur case showed that with intensified medical therapy and CPAP use there was improvement of $O S^{\prime} S$ and over time resulted in significant improvement in frequency of CSA, improvement in oxygen saturation and cardiac function (EF).

0 ther treatment modalities like cardiac transplantation usually eliminate central sleep apneas $(66,67)$. Another mode of therapy found useful in patients with mild left ventricular systolic dysfunction with CSA is atrial overdrive pacing (68).

In conclusion, our case depicts the presence of both $O S A$ and CSA in a patient of severe H F with unmasking of CSA following CPAP use. Further with continued use of overnight CPAP, intensive medical therapy for $\mathrm{HF}$ and regulated thyroid replacement therapy follow up PSG (after three months) demonstrated subjective 
and objective $(A B G \& P S G)$ improvement with significant reduction in periodic breathing.

\section{Authors' affiliations}

Dr. D. Bhattacharya, Sr. Chest Physician

Dr. M. K. Sen, Sr. Chest Physician

Dr. S. Chakrabarti, Sr. Chest Physician

Dr. N. K. Gupta, Sr. Chest Physician

Dr. J. C. Suri, Sr. Chest Physician \& Head of Department. Department of Pulmonary, Critical Care \& Sleep Medicine, Vardhman Mahavir Medical College \& Safdarjang Hospital, N ew Delhi

\section{References}

1. Shahrok Javaheri, Heart failure and sleep apnea: emphasis on practical therapeutic options. Clin Chest Med 24 (2003) 207-222.

2. Tremel F, Pepin J-L, Veale D, N iyam B, Siclie J P, Mallion JM et al. High prevalence and persistence of sleep apnea in patient referred for acute left ventricular failure and medically treated for 2 months. Eur Heart]. 1999: 20:120109.

3. Don D. Sin, Fabia Fitzgerald, John D. Parker et al. Risk Factors for Central and Obstructive Sleep Apnea in 450 Men and Women with Congestive Heart Failure. AmJ Respir Crit Care Med 1999;160:1101-1106.

4. Javaheri S, Parker TJ, Liming JD, et al. Sleep apnea in 81 ambulatory male patients with stable heart failure: types and their prevalence's, consequences and presentations. Circulation. 1998;97:2154-2159.

5. Katherian Farier Angela Campbell, Brenden Yeebal et al. Sleep Disordered breathing occurs frequently in Stable outpatients with CHF. Chest 2005;128:2116-2122.

6. Flemmons $\mathbf{W} \mathbf{W}$, Whitelaw WA, Brant R, Remmers JE. Likelihood ratios for a sleep apnea clinical prediction rule. Am J. Respir Crit Care Med. 1994;150:1279-85.

7. Fujiwara $\mathbf{Y}$, Kahitruba N, Motoyama $S$, O hinata $Y$ et al. Value of mesopharyngometry for obstructive sleep apnea syndrome. Togawak (ed) Sleep Apnea and Rhonchopathy. Basal Karger;1993:89-99.

8. T. Douglas Bradley, J ohn S, Floras et al. Sleep Apnea and Heart Failure - Part I: O bstructive Sleep Apnea. Circulation. 2003;107:1671-1678.

9. Hunt HA, Baker DW, Chin MH, et al. ACC/AHA guidelines for the evaluation and management of chronic heart failure in the adult: executive summary: a report of the American College of Cardiology/American Heart Association Task Force on Practice Guidelines (Committee to Revise the 1995 Guidelines for the Evaluation and Management of Heart Failure). Circulation. 2001;104:2996-3007.

10. Remmers JE, Degroot WJ, Sauerland EK et al. Pathogenesis of upper airway occlusion during sleep. J Appl Physiol. 1978;44:931-938.
11. Horner RL, Mohiaddin RH, Lowell DG, et al. Sites and sizes of fat deposits around the pharynx in obese patients with obstructive sleep apnea and weight matched controls. Eur Respir J. 1989;2:613-622.

12. Alex CG, O nal E, lopata M. Upper airway occlusion during sleep in patients with Cheyne-stokes respiration. Am Rev Respir Dis. 1986;133:42-45.

13. Shepard J W J r, Pevernagie DA, Stanson AW, et al. Effects of changes in central venous pressure on upper airway size in patients with obstructive sleep apnea. Am J Respir Crit Care Med. 1996;153:250-254.

14. Solin P, Bergin P, Richardson M, et al. Influence of pulmonary capillary wedge pressure on central apnea in heart failure. Circulation. 1999;99:1574-1579.

15. Bradley TD, Phillipson EA. Central Sleep Apnea. Clin Chest Med. 1992;13:493-505.

16. Naughton $\mathbf{M}$, Benard $D$, Tam A, et al. Role of hyperventilation in the pathogenesis of central sleep apneas in patients with congestive heart failure. Am Rev Respir Dis. 1993;148:330-338.

17. Hall MJ, Xie A, Rutherford R, et al. Cycle length of periodic breathing in patients with and without heart failure. Am J Respir Crit Care Med. 1996;154:376-381.

18. Klein $\mathbf{O}$ et al. Untersuchungen uber das Chene stoche atmungphan owen. Verhandl d. deutsch. Ges. f. inn Med. 42:217, 1930

19. William W. Pryor. Cheyne stokes respiration in patients with cardiac enlargement and prolonged circulation time. Circulation 1951;4:233-38.

20. Javaheri S. Central Sleep Apnea in Congestive Heart Failure: Prevalence, Mechanisms, Impact and Therapeutic O ptions. Semin Respir Crit Care Med. 2005;26(1):44-55.

21. Javaheri S, Sleep-related breathing disorders in heart failure, In: Mann DL, ed. heart Failure, A companion to Braunwald's Heart Disease. Philadelphia: WB Saunders; 2004:471-487.

22. T. Douglas Bradley, J ohn S. Floras et al. Sleep Apnea and heart Failure - Part II: Central Sleep Apnea. Circulation. 2003;107:1822-1826.

23. Harrison TR, King CE, Calhoun JA, et al. Congestive heart failure: Cheyne-strokes respiration as the cause of dyspnea at the onset of sleep. Arch Int Med. 1934;53:891-910.

24. Javaheri S, Parker TJ, Wexler L, et al. O ccult sleepdisordered breathing in stable congestive heart failure. Ann Intern Med 1995;122:487-492. Erratum: Ann Intern Med 1995;123:77.

25. Ruzena Tkacova, Mitra Niroumand, Geraldo LorenziFilho, T. Douglas Bradley, et al. O vernight shift from O bstructive to Central Apneas in Patients with heart failure. Circulation 2001;103:238-243.

26. Hall MJ, Xie A, Rutherford R, et al. Cycle length of periodic breathing in patients with and without heart failure. Am J Respir Crit Care Med. 1996;154:376-381.

27. Somers V. To sleep, perchance to breathe: implications for the failing heart. Am J Respir cit Care Med.

Indian Journal of Sleep M edicine (IJSM ), Vol. 1, N o. 2, 2006 
116 An Interesting Case of Central and O bstructive Sleep Apnea in A Patient of Congestive HeartFailure with Unmasking of CSA'sFollowing CPAPUse

1999:160:1077-1078.

28. Tkacova, Hall MJ, Lin PP et al. Left ventricular volume in patients with heart failure and Cheyne Stokes respiration during sleep. Am J. Respir Crit Care Med 1997;156:15491555.

29. Drr WC, Males JL, Imes NK, Myxedema and obstructive sleep apnea. Am J Med 1981; 70:2-6

30. Skatrud J, Iber C, Ewart R, Thomas G, et al. Disordered breathing during sleep in hypothyroidism. Am Rev Respir Dis 1981;124:325-9

31. Zwillich CW, Pierson DJ, Hofeldt FD, Lufkin EG, Well JV, Ventilatory control in myxedema and hypothyroidism. N Engl J Med 1975;292:662-5.

32. Onal E, Lopata M, O 'Connor T, Pathogenesis of apneas in hypersomnia-sleep apnea syndrome. Am Rev Respir Dis 1982;125:167-74

33. Issa FG, Sullivan CE, Alcohol, snoring and sleep apnea. J N eurol N eurosurg Psychiatry, 1985;45:353-359.

34. Smith PL, Gold AR, Meyers DA, et al. Weight loss in mildly to moderately obese patients with obstructive sleep apnea. Ann Int Med. 1985;103(Pt 1):850-855.

35. Engleman HM, Martin SE, Deary IJ et al. Effect of continuous positive airway pressure treatment on daytime function in sleep apnoea/hypopnoea syndrome. Lancet 1994;343:572575.

36. Pepperell JC, Ramdassingh - Dow S, Crosthwaite N, et al. Ambulatory blood pressure after therapeutic and subtherapeutic nasal continuous positive airway pressure for obstructive sleep apnoea: a randomized parallel trial. Lancet, 2002;359:204-210.

37. Kraici H, Hedner J, Peker Y, et al. Comparison of atenolol, amlodipine enalapril, hydrochlorothiazide, and losartan for antihypertensive treatment in patients with obstructive sleep apnea. Am J Respir Crit Care Med. 2000;161:1423-1428.

38. Malone S, Liu PP, Holloway R, et al. O bstructive sleep apnoea in patients with dilated cardiomyopathy: effects of continuous positive airway pressure. Lancet. 1991;338:14801484.

39. Javaheri S. Treatment of central sleep apnea in heart failure. Sleep 2000;23:S224-S227.

40. Sin DD, Logan AG, Fitzgerald FS et al. Effects of continuous positive airway pressure on cardiovascular outcomes in heart failure patients with and without Cheyne-Strokes respiration. Circulation. 2000;102:61-66.

41. Naughton MT, Liu PP, Bernard DC et al. Treatment of congestive chest failure and Cheyne-Stokes respiration during sleep by continuous positive airway pressure. Am J Respir Crit Care Med. 1995;151:92-97.

42. Javaheri S, Parker TJ, Wexler L, et al. Effect of theophylline on sleep-disordered breathing in heart failure. $N$ Engl J Med 1996;335:562-567

43. White DP, Zwillich CS, Pickett CK, Douglas NJ, Findley LJ, Weil JV. Central sleep apnea improvement with acetazolamide therapy. Arch Intern Med 1982;182:18161819.

Indian Journal of Sleep M edicine (IJSM), Vol. 1, N o. 2, 2006
44. DeBacker WA, Verbraecken J, Lwillemen M, Wittesaele W, DeCock W et al. Central apnea index decreases after prolonged treatment with Acetazolamide. Am J Respir Crit Care Med 1995;151:87-91.

45. Nkere UU, Hall MCS, Corris PA. Sleep apnoea/hypopnoea syndrome: a potential cause of graft failure following heart transplantation. EurJ Cardiothorac Surg 1998;13:203-205.

46. Keurl A Franklin, Peter Eriksson, Carin Sahlin and Rune Lungren. Reversal of Central Sleep Apnea with oxygen. Chest 1997;111:163-69.

47. Javaheri S, Ahmed M, Parker TJ et al. Effects of nasal $\mathrm{O}_{2}$ on sleep-related disordered breathing in ambulatory patients with stable heart failure. Sleep 1999;22:1101-1106.

48. Hanly PF, Millar W, Steljes DG, et al. The effect of oxygen on respiration and sleep in patients with congestive heart failure. Ann Intern Med 1989;111:777-782.

49. Khoo MC, Kim TS, Berry RB. Spectral indices of cardiac autonomic function in obstructive sleep apnea. Sleep 1999;22:443-451.

50. Andreas S, Von Zur Muhlen F, Stevens J, et al. Nocturnal oxygen and hypercapnic ventilatory response in patients with congestive heart failure. Respir Med 1998;92:426431.

51. Andreas S, Bingeli C, Mohacsi P, Lischer TF, Noll G. Nasal oxygen and muscle sympathetic nerve activity in heart failure. Chest 2003;123:366-371.

52. Staniforth AD, Kinneart WJM, Hetmanski DJ, et al. Effect of oxygen on sleep quality, congnitive function and sympathetic activity in patients with chronic heart failure and Cheyne-stokes respiration. Eur Heart J 1998;19:922928.

53. S. Andreas, K. Weldd, G. Hagenah, S. Heindi. Treatment of Chynes Strokes respiration with nasal oxygen and $\mathrm{CO}_{2}$. Eur Respir J. 1998;12:414-419.

54. Steens BD, Millar TW, SuX et al. Effect of inhaled $3 \% \mathrm{CO}_{2}$ on CSR in CHR. Sleep 1994;17:61-60.

55. Teschler H, Dohring J, Wang $Y \mathbf{M}$ et al. Adaptive pressure support servo ventilation: a novel treatment for Chynes Stokes respiration in heart failure. Am J. Respir Dis 2001; 164: 614-619.

56. Naughton MT, Rahman MA, Hara K et al . Effect of continuous airway pressure on intra thoracic and transmura pressures in patients of congestive heart failure. Circulation. 1995; 91 : 1725-1731.

57. Bradley TD, Holloway RM, McLaughlin PR et al. Cardiac output response to continuous positive airway pressure in congestive heart failure. Am Rev. Respir Dis. 1992; 145: 377-382.

58. Kaye DM, Mansfield D, Aggarwal A et al. Acute effects of continuous airway pressure on cardiac sympathetic tone in congestive heart failure Circulation. 2001; 103: 2336-2338.

59. Mehta S, Liu PP, Fitzgerald FS, et al. Effects of continuous posiive airway pressure on cardiac volumes in patients with ischemic and dilated cardiomyopathy. Am J Respir Crit Care Med. 2000;161:128-134. 
60. Javaheri S. Effects of continuous positive airway pressure on sleep apnea and ventricular irritability in patients with heart failure. Circulation 2000;101:392-397.

61. Naughton MR, Benard DC, Liu PP, et al. Effects of nasal CPAP on sympathetic activity in patients with heart failure and central sleep apnea. Am J Respir Crit Care Med. 1995;152:473-479.

62. Tkacova R, Liu PP, N aughton MT, et al. Effect of continuous positive airway pressure on mitral regurgitant fraction and atrial natriurelle peptide in patients with heart failure. J Am Coll Cardiol. 1997; 10:739-745.

63. T. Douglas Bradley, Alexander G. Logan, R. John Kimoff et al. Continuous Positive Airway pressure for Central Sleep Apnea and Heart Failure. NEJM 2005;353:2025-2033.

64. Don D.Sin, Alexander G. Logan, Fabia S. Fitsgerald et al.
Effect of continuous CPAP on Cardiovascular outcomes in heart failure patients with and without Cheyne Strokes respiration. Circulation 2000;102:61-66.

65. PJ. Hanley and NS zuberi Khokhar. Increased mortality associated with CSR in patients with CHF. Am J. Respir Crit Care Med. 1996;153:272-276.

66. Mansfield DR, Solin P, Roebuck T, Bergin P, Kaye DM, Naughton MT. The effect of successful heart transplant treatment of heart failure on central sleep apnea. Chest 2003;124:1675-1681.

67. Braver HM, Brandes WC, Kubiet MA, et al. Effect of cardiac transplantation on Cheyne-Stokes respiration occurring during sleep. Am J Cardiol 1995;76:632-634.

68. Garrigue $\mathbf{S}$, Bordier $P$, Jais $P$ et al. Benefit of atrial pacing in sleep apnea syndrome. N Engl J Med 2002;346:404412. 